\title{
Erratum to: Effects of Minor Sc and Zr on the Microstructure and Mechanical Properties of Al-4.6Cu-0.3Mg-0.6Ag Alloys
}

Sheng-Long Lee, Chih-Ting Wu, and Yu-Te Chen

Erratum to: J. of Materi Eng and Perform (2015)

24:1165-1172

DOI: 10.1007/s11665-014-1364-2

The third author's correct English name is Yu-Te Chen, not Yu-De Chen as published in the original version.

The online version of the original article can be found under doi:10.1007/s11665-014-1364-2.

Sheng-Long Lee, Department of Mechanical Engineering/Institute of Materials Science and Engineering, National Central University, Jhongli, Taiwan; Chih-Ting Wu, Department of Vehicle Engineering, Army Academy R.O.C, Jhongli, Taiwan; and Yu-Te Chen, Department of Mechanical Engineering, National Central University, Jhongli, Taiwan. Contact e-mail: shenglon@cc.ncu.edu.tw. 